\title{
Photochemical Nature of Parietopsin
}

\author{
Kazumi Sakai $^{\dagger}$, Yasushi Imamoto $^{\dagger}$, Chih-Ying Su $^{\ddagger}, \S$, Hisao Tsukamoto ${ }^{\dagger}, \|$, Takahiro \\ Yamashita $^{\dagger}$, Akihisa Terakita ${ }^{\dagger, \perp}$, King-Wai Yau $^{\ddagger}$, and Yoshinori Shichida ${ }^{*}, \dagger$ \\ tDepartment of Biophysics, Graduate School of Science, Kyoto University, Kyoto 606-8502, \\ Japan \\ ‡Department of Neuroscience, Johns Hopkins University School of Medicine, Baltimore, MD \\ 21205, USA.
}

\begin{abstract}
Parietopsin is a non-visual green-light-sensitive opsin closely related to vertebrate visual opsins, and was originally identified in lizard parietal-eye photoreceptor cells. To obtain insight into the functional diversity of opsins, we investigated by UV-visible absorption spectroscopy the molecular properties of parietopsin and its mutants exogenously expressed in cultured cells, and compared to vertebrate and invertebrate visual opsins. Our mutational analysis revealed that the counterion in parietopsin is the glutamic acid (Glu) in the second extracellular loop, corresponding to Glu181 in bovine rhodopsin. This arrangement is characteristic of invertebrate rather than vertebrate visual opsins. The photosensitivity and the molar extinction coefficient of parietopsin were also lower than those of vertebrate visual opsins, features likewise characteristic of invertebrate visual opsins. On the other hand, irradiation of parietopsin yielded meta-I, meta-II, and meta-III intermediates after batho- and lumi-intermediates, similar to vertebrate visual opsins. The $\mathrm{pH}$-dependent equilibrium profile between meta-I and meta-II intermediates was, however, similar to that between acid and alkaline metarhodopsins in invertebrate visual opsins. Thus, parietopsin behaves as an "evolutionary intermediate" between invertebrate and vertebrate visual opsins.
\end{abstract}

\begin{abstract}
Animals have retinal-based, light-sensing proteins called opsins for providing light-mediated information about the environment (1). The most-extensively studied of these is vertebrate rhodopsin, the visual opsin in rod photoreceptor cells for twilight vision. Parietopsin is a green-light-sensitive opsin first identified in the lizard parietal eye (2), and thought to be involved in the global detection of dawn and dusk, sky polarization pattern and magnetoreception, rather than vision (3-5). In addition to its functional significance, phylogenetic analysis has shown that parietopsin is situated in an interesting position in opsin evolution by belonging to a cluster of vertebrate non-visual opsins closely related to the vertebrate visual-opsin subgroup (Figure 1). However, the molecular properties of parietopsin remain largely unknown.
\end{abstract}

\footnotetext{
*To whom correspondence should be addressed: Telephone: +81-75-753-4213. Fax: +81-75-753-4210. shichida@rh.biophys.kyotou.ac.jp .

\$Present Address: Department of Molecular, Cellular and Developmental Biology, Yale University, New Haven, CT 06520, USA "Present Address: Institute for Molecular Science, National Institutes of Natural Sciences, 38 Nishigo-Naka, Myodaiji, Okazaki 444-8585, Japan

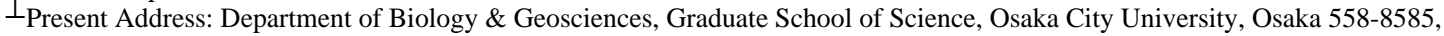
Japan

Supporting information available The absorption spectra of Xenopus parietopsin (Figure S1) and Q113Y mutant of lizard parietopsin (Figure S2). This material is available free of charge via the Internet at http://pubs.acs.org.

Conflict of Interest Disclosure The authors declare no competing financial interest.
} 
Opsins are seven- $\alpha$-helical-transmembrane proteins containing retinal as a light-absorbing chromophore. They have a highly conserved lysine residue in helix VII, where the retinal chromophore binds through a Schiff-base linkage. This Schiff base is protonated in visiblelight-absorbing opsins, with the proton being stabilized by a nearby negatively-charged glutamic (or aspartic) acid called 'counterion'. Several lines of evidence indicate that the glutamic acid at position 181 in the second extracellular loop serves as the counterion in most opsins (6), while the glutamic acid at position 113 in helix III serves as the counterion in vertebrate visual opsins (7-9). In the latter opsins, the counterion at position 113 forms a salt bridge between helices III and VII. Light absorption causes a cis-trans isomerization of retinal, which triggers proton transfer from the Schiff base to the counterion, resulting in breakage of the salt bridge. Subsequently, the protein moiety undergoes a thermal reaction, culminating in a large conformational change to enhance its G-protein-activation efficiency $(6,10)$.

So far, the photochemical and subsequent thermal reactions of vertebrate visual opsins with a position-113 counterion have been extensively investigated in bovine rhodopsin (belonging to the vertebrate visual opsin subgroup). Likewise, the reactions of opsins that do not have a position-113 counterion (Figure 1) have been investigated in squid rhodopsin (belonging to the invertebrate visual opsin subgroup). A comparison between these two opsins has indicated that they are similar with respect to the primary photochemical reaction, but quite different with respect to the late thermal reactions, especially the formation of the G-protein-activating state. In fact, this activating state for bovine rhodopsin is a UV-lightabsorbing intermediate (meta-II) with a deprotonated retinylidene Schiff base $(11,12)$, while that for squid rhodopsin, called acid metarhodopsin, is a visible-light-absorbing intermediate with a protonated retinylidene Schiff base (13). Moreover, irradiation of vertebrate meta-II converts into meta-III (which is also formed thermally from meta-II) instead of the original dark-state rhodopsin, whereas squid acid metarhodopsin photo-converts back to the original dark-state rhodopsin (14). Pigments exhibiting the latter photochromism between the resting and active states are referred to as 'bistable' pigments (15). Peropsin (16), Opn5 (neuropsin) $(17,18)$ as well as $\mathrm{G}_{0}$-coupled rhodopsin (19) exhibit bistability similar to squid rhodopsin. In the vertebrate visual and non-visual opsins/encephalopsin group, pinopsin shows a photoreaction similar to that of visual opsins (20), while parapinopsin exhibits bistability (21). In addition, we have recently found that VA opsin is not bistable(22). Although parietopsin is closely related to these non-visual opsins, it forms a different phylogenetic subgroup. Thus, characterization of its reaction process will provide insight into the molecular evolution of vertebrate visual opsins.

In the present study, we investigated the photochemical properties of parietopsin by means of low-temperature, time-resolved UV-visible absorption spectroscopy. Our experiments show that parietopsin is a bleachable (monostable) pigment but exhibits some properties characteristic of bistable pigments.

\section{Materials and Methods}

\section{Opsin preparation}

Parietopsin cDNAs from side-blotched lizard (Uta stansburiana) were prepared as reported previously (2). Total RNAs extracted from the brain of zebrafish (Danio rerio) and western clawed frog (Xenopus tropicalis) were reverse transcribed to cDNAs by using oligo (dT) primer. The full-length ORF fragments of parietopsin genes were obtained from the cDNA mixtures by PCR amplification with gene-specific primers designed according to the mRNA sequence of $X$. tropicalis (GenBank accession number: DQ284780) and the predicted sequence from a genomic sequence of $D$. rerio (NCBI Reference Sequence: XM_681591.1). The primer sequences were as follows: 5'-ATGGATGGCAATAGCACCACCCCTG-3' 
(forward) and 5'-CTATGCTGGAGCCACTTGATTGGTT-3' (reverse) for cloning of the $X$. Tropicalis parietopsin, and 5'-ATGGAGAACTTTGCTAAAACTGAGC-3' (forward) and 5'-TCAGACTGGATTGACCCTGCTTTGG-3' (reverse) for cloning of the D.rerio parietopsin. Parietopsin cDNAs were tagged by the epitope sequence of the antibody rho1D4 at the C-terminus and inserted into a mammalian expression vector, pMT4. The cDNA encoding bovine rhodopsin was inserted into the expression vector, pUSR $\alpha$. Sitedirected mutants were prepared using the QuikChange kit (Agilent Technologies) according to the manufacturer's instructions.

The expression and purification of pigments were performed as previously described (23). The plasmid DNA was transfected into HEK293T cells by the calcium phosphate method, and after cultivation for 48 hours the transfected cells were collected by centrifugation. To regenerate pigments, cells were incubated with an excess amount of 11-cis-retinal for more than 12 hours at $4{ }^{\circ} \mathrm{C}$. The regenerated pigments were extracted with $1 \%$ DM buffer [ $1 \%(\mathrm{w} /$ v) DM in buffer PM (50 mM HEPES, $140 \mathrm{mM} \mathrm{NaCl}, 3 \mathrm{mM} \mathrm{MgCl}_{2}$, $\mathrm{pH} 6.5$ or 7.0)] or CHAPS/PC buffer $[0.75 \%$ (w/v) CHAPS and $1 \mathrm{mg} / \mathrm{ml}$ PC in buffer PM] and subjected to the rho1D4-conjugated agarose column chromatography for purification. The column was washed with $0.02 \%$ DM buffer or $0.75 \%$ CHAPS/PC buffer and pigments were eluted with the same buffer containing synthetic peptides corresponding to the C-terminal sequence of bovine rhodopsin.

PC liposomes containing parietopsin were prepared by dialysis of the purified parietopsin with CHAPS/PC buffer against a 2000-fold volume of PM buffer at $\mathrm{pH} 6.5$ for 2 days.

Membrane fragments containing parietopsin were prepared from HEK293T cells. Cells transfected with parietopsin were suspended in 50\% (w/v) sucrose in PM buffer ( $\mathrm{pH} 7.0$ ), sonicated and centrifuged. The supernatants containing the membrane fragments were collected and precipitated by a three fold dilution with PM buffer, followed by centrifugation. The precipitated membranes were collected for spectroscopic study.

\section{UV-visible spectroscopy}

Absorption spectra were recorded on MPS-2000 (Shimadzu), UV-2400 (Shimadzu) or U-4100 (Hitachi) spectrophotometers. Samples were photoexcited with light from a 1-kW tungsten-halogen projector lamp, which had passed through a glass cut off filter and/or an interference filter.

Light intensities of photoexcitation were measured by using an optical power meter (Nova laser power meter and energy meter, Ophir Optronics) with a power sensor (30A-P-17, Ophir Optronics) set at the position of samples.

For measurements at low temperatures $\left(-190-0^{\circ} \mathrm{C}\right)$, an optical cryostat (Optistat DN, Oxford Instruments) connected to a temperature controller (ITC502, Oxford Instruments) was set in a UV-2400 spectrophotometer. Opal glass was used to compensate for light scattering by cracks in the sample formed at liquid nitrogen temperature. To avoid the formation of micro crystals, samples were purified with CHAPS/PC buffer containing $20 \%$ $(\mathrm{w} / \mathrm{v})$ glycerol at $\mathrm{pH} 6.5$. Glycerol was further added at a final concentration of 91 and $50 \%$ $(\mathrm{w} / \mathrm{v})$ for the measurements below -80 and $-20^{\circ} \mathrm{C}$, respectively.

\section{Time-resolved spectroscopy}

Transient spectra of parietopsin showing the behavior of the later intermediates were recorded with a laboratory-built time-resolved spectrophotometer. The monitoring light was generated by a UV-visible fiber light source (L10290, Hamamatsu Photonics). It was passed through the sample cell and focused on a polychromater (Imaging Spectrograph 250is, 
Chromex), and detected by a high-speed CCD camera (C10000SP, Hamamatsu Photonics). Using this spectrophotometer, the full spectra $(930-208 \mathrm{~nm})$ with a wavelength resolution of $0.353 \mathrm{~nm}$ were able to be recorded at a time interval of $100 \mathrm{sec}$. The temperature of the sample was kept at $0{ }^{\circ} \mathrm{C}$ by a Peltier-controlled cuvette holder (qpod, Ocean Optics). The photoreaction was initiated with a flash of light from a xenon flash lamp (pulse width: 170 sec, Nissin Electronic) filtered by a glass cut-off filter O54 (Toshiba) or with a $532 \mathrm{~nm}$ light pulse ( $\sim 5 \mathrm{~ns})$ from a YAG laser (Minilite-I, Continuum).

\section{pH-titration of parietopsin and photoproducts}

Samples were purified with CHAPS/PC buffer containing 20\% (w/v) glycerol at various $\mathrm{pHs}$. The $\mathrm{pH}$-titrations of dark states of parietopsin and mutants were carried out by measuring the absorption spectra with a UV2400 spectrophotometer at $0{ }^{\circ} \mathrm{C}$. For the $\mathrm{pH}-$ titration of the photoproduct, the amount of deprotonated photoproduct was estimated from the transient spectra in the visible region. The ratio of protonated photoproduct was plotted against $\mathrm{pH}$ and fitted with a Henderson-Hasselbalch equation.

\section{Photosensitivity, molar extinction coefficient and quantum yield}

Photosensitivity $(S)$ of parietopsin was determined by UV-visible spectroscopy using a Hitachi U-4100 spectrophotometer as previously described (24). The samples were purified with $0.02 \%$ DM buffer at $\mathrm{pH} 6.5$, supplemented with $50 \mathrm{mM}$ hydroxylamine, and kept in the dark at $0{ }^{\circ} \mathrm{C}$ for 3 hours. Less than $1 \%$ of rhodopsin or parietopsin was bleached in this condition. Then, irradiation of the sample with a monochromatic light passed through an interference filter ( $500 \mathrm{~nm}$; half-band width, $5 \mathrm{~nm}$; Optical Coatings Japan) for $2.5 \mathrm{~min}-5$ min was repeated several times, and finally, the sample was completely bleached by intense $>500 \mathrm{~nm}$ light. The amount of residual pigment after each irradiation was plotted against the number of incident photons on a semilogarithmic scale and fitted with a line. The slope of the regression line gives the rate of photobleaching, which is proportional to $S$ of the pigment at the wavelength of irradiation light. The rates of photobleaching of bovine rhodopsin and parietopsin were measured using the same experimental setup, and $S$ of parietopsin relative to bovine rhodopsin was determined.

The molar extinction coefficient $(\varepsilon)$ of parietopsin was determined by the acid denaturation method $(8,25)$ at $10{ }^{\circ} \mathrm{C}$. After recording the dark state spectrum, a small amount of $2 \mathrm{~N} \mathrm{HCl}$ was added to the sample for acidification (final $\mathrm{pH}$ of $<1.5$ ), by which pigments were denatured but the protonated Schiff base of the chromophore was not hydrolyzed. Because the protein moiety is denatured, all pigments show identical acid-denatured spectra with a peak at around $440 \mathrm{~nm}$. By comparing the denatured spectra of parietopsin and bovine rhodopsin, $\varepsilon$ of native parietopsin was estimated.

The quantum yield $(\phi)$ of pigments was calculated from the following expression:

$$
S \propto \varepsilon \times \phi
$$

The values of $\phi$ and $\varepsilon$ of bovine rhodopsin used for these calculations were 0.65 , and 40600 $\mathrm{M}^{-1} \mathrm{~cm}^{-1}$, respectively $(26,27)$.

\section{Results}

\section{Identification of Counterion in Parietopsin}

Parietopsin has Gln at position 113 and Glu at position 181 (Figure 1), suggesting that Glu181 acts as the counterion. Its E181Q mutant (i.e., residues 113/181 being Q/Q) showed 
a significant shift in the $\mathrm{p} K_{\mathrm{a}}$ of the protonated Schiff base towards acidic $\mathrm{pH}$, resulting in a UV shift of $\lambda_{\max }$ upon alkalization (Figures $2 \mathrm{~A}$ and $2 \mathrm{~B}$ ). At $\mathrm{pH} 7.5$, the absorbance at the visible region of E181Q significantly decreased but did not change in wild-type parietopsin (Figures 2A and 2B). These results conclusively showed that Glu181 is the counterion in parietopsin.

Mutational experiments on amphioxus $\mathrm{G}_{\mathrm{o}}$-coupled rhodopsin and peropsin have shown that Glu introduced at position $113 \mathrm{can}$ act as a counterion when the original counterion (Glu181) is removed (6). Thus we examined the same pH-effect on Q113E/E181Q parietopsin (E/Q) (Figure 2C). This double-mutant exhibited a 25-nm blue-shift in absorption maximum from wild type $(495 \mathrm{~nm})$ at $\mathrm{pH} 7.0$, and the absorption spectrum did not show a pH-dependence. Therefore, Glu113 instead of Glu181 acts as the counterion in the Q113E/E181Q parietopsin, similar to $\mathrm{G}_{\mathrm{o}}$-coupled rhodopsin and peropsin.

We examined Q113E parietopsin and found that its absorption spectrum was $\mathrm{pH}$-dependent (Figure 2D). At acidic $\mathrm{pH}$ (5.3 - 6.5), the $\lambda_{\max }$ of Q113E parietopsin became blue-shifted by $20 \mathrm{~nm}$ from wild-type, suggesting that Glu113 is located near the Schiff base and affects the electrostatic environment of the Schiff base. Interestingly, the spectrum was further blueshifted at alkaline $\mathrm{pH}$ (8.4), in contrast to the stable absorption spectrum of bovine rhodopsin in this $\mathrm{pH}$ range. Although the mechanism of this blue-shift is not clear yet, this indicates that the interactions between the Schiff base, Glu113, and Glu181 in Q113E parietopsin are different from those of vertebrate visual opsins.

A noticeable characteristic of parietopsin is its red-shifted $\lambda_{\max }(522 \mathrm{~nm})$ with respect to rhodopsin and pinopsin (2). To look into this point, we cloned the parietopsin gene from also zebrafish (D. rerio) (Accession number: AB693171) and western clawed frog (X. tropicalis) and expressed both in HEK293T cells. We could not obtain recombinant protein of zebrafish parietopsin, but successfully expressed and purified Xenopus parietopsin, which had $\lambda_{\max }$ at $520 \mathrm{~nm}$ (Figure S1). Therefore, the red-shifted $\lambda_{\max }$ is likely to be a common feature of parietopsins.

From phylogenetic analysis, we speculated that the ancestor of vertebrate visual and nonvisual opsins maintained a Tyr at position 113 just after diversification from other opsin groups. The expression of the Q113Y mutant was poor, but its $\lambda_{\max }$ was located below 500 $\mathrm{nm}$ (Figure S2), indicating that Gln113 may contribute to the red-shifted $\lambda_{\max }$ in parietopsin.

\section{Photoreceptive ability}

The above results showed that Glu181 of parietopsin acts as a counterion, which is similar to opsins other than the vertebrate visual opsins. It is known that the photosensitivity of invertebrate visual opsins such as squid and octopus rhodopsins is significantly lower than that of vertebrate visual opsins $(28,29)$. Therefore, we examined the photosensitivity of lizard parietopsin.

The photosensitivity $(S)$ was evaluated by the amount of pigment converted to the bleaching intermediates as a function of incident photon intensity. Parietopsin and bovine rhodopsin samples were supplemented with $50 \mathrm{mM}$ hydroxylamine to dissociate the potential visiblelight-absorbing intermediates into retinal oxime and apoprotein. Before irradiation, the samples were incubated for 3 hours in the presence of $50 \mathrm{mM}$ hydroxylamine in darkness to examine for stability against hydroxylamine. For both pigments, the amount of bleached pigment after 3 hours was less than $1 \%$ of total pigment. Each sample was then irradiated with 500-nm light, which bleached the pigments into all-trans-retinal oxime and apoprotein as shown by the formation of a peak at about $360 \mathrm{~nm}$ (Figures 3A and 3B). The amount of residual pigment was plotted against the incident photon number on a semi-logarithmic scale 
and the relation fitted linearly (Figure 3C). From the slopes for rhodopsin and parietopsin, the relative $S$ of parietopsin at $500 \mathrm{~nm}$ with respect to bovine rhodopsin was determined to be $0.63 \pm 0.02$. Using the absorbance ratio at $500 \mathrm{~nm}$ to $520 \mathrm{~nm}, S$ of parietopsin at $\lambda_{\max }$ $(520 \mathrm{~nm})$ was calculated to be $0.69 \pm 0.02$ of that of bovine rhodopsin at $\lambda_{\max }(500 \mathrm{~nm})$. Thus $S$ of parietopsin is significantly lower than those of bovine rhodopsin and cone visual pigments $(25,30,31)$.

The molar extinction coefficient $(\varepsilon)$ represents the probability that a chemical species absorbs a photon at a given wavelength. $\varepsilon$ of parietopsin was determined by the acid denaturation method $(8,25)$. Using $\varepsilon$ of bovine rhodopsin at $500 \mathrm{~nm}\left(40600 \mathrm{M}^{-1} \mathrm{~cm}^{-1}\right)(27)$, $\varepsilon$ of parietopsin was determined to be $31700 \pm 500 \mathrm{M}^{-1} \mathrm{~cm}^{-1}$ at $520 \mathrm{~nm}\left(\lambda_{\max }\right)$ and $29000 \pm$ $500 \mathrm{M}^{-1} \mathrm{~cm}^{-1}$ at $500 \mathrm{~nm}$ (Figure 3D), which were significantly lower than those of bovine rhodopsin and cone pigments $(25,30,31)$, but close to those of invertebrate visual opsins $(28,32,33)$ and chicken Opn5 (17) in other opsin groups (Figure 1).

The quantum yield $(\phi)$ is defined as the probability that isomerization occurs after the absorption of a photon. Bovine rhodopsin has $\phi=0.65$, which is 3-4 times higher than that of the protonated Schiff base of retinal in solution $(0.18-0.23)(26,34)$. The high quantum yield is achieved by the electrostatic environment around 11-cis-retinal in visual pigments. As $S$ $\infty \varepsilon \times \phi, \phi$ of parietopsin was calculated to be $0.57 \pm 0.02$. This value is close to that of bovine rhodopsin $(0.65)$ as well as octopus rhodopsin $(0.69)$ (32). These results showed that parietopsin exhibits photoreceptive characteristics similar to those of invertebrate visual opsins such as squid and octopus rhodopsins with a counterion at position 181 .

\section{Primary photochemical reaction at liquid-nitrogen temperature}

To compare the primary photochemical reaction of parietopsin with those of other pigments, the reaction was observed with low-temperature spectroscopy (Figure 4). Lizard parietopsin was cooled to $-185^{\circ} \mathrm{C}$ and irradiated with 500-nm light. Irradiation caused a red-shift of the spectrum (curve 2 in Figure 4), indicating the formation of a photo-steady-state mixture containing mainly the batho-intermediate (bathoparietopsin). Subsequent irradiation of this mixture with red light resulted in the formation of a mixture containing mainly a blueshifted photoproduct (isoparietopsin) (Figure 4, curve 3). Re-irradiation of this mixture with 500 -nm light caused the formation of a mixture similar to that produced by the first 500-nm irradiation (Figure 4, curve 4), indicating that batho-, iso- and original parietopsins are interconvertible by light at liquid-nitrogen temperature. Therefore, the photoreaction of parietopsin is similar to those observed for both vertebrate and invertebrate visual opsins $(35,36)$.

\section{Late intermediates of parietopsin}

In vertebrate rhodopsins, warming the batho-intermediate results in sequential formations of lumi, meta-I, meta-II and meta-III intermediates. On the other hand, invertebrate rhodopsin converts to a stable intermediate called acid metarhodopsin through batho, lumi and LM intermediates $(13,37)$. As we have shown that parietopsin shares some of the properties of invertebrate opsins, it is of interest whether the reaction process of parietopsin is similar to that of invertebrate rhodopsin or vertebrate rhodopsin.

The photo-steady-state mixture containing mainly bathoparietopsin was warmed stepwise, resulting in the formation of several intermediates (Figures 5A and 5B). The absorption maximum of the mixture containing mainly bathoparietopsin $(600 \mathrm{~nm})$ was blue-shifted as the temperature increased, indicating the formation of the next intermediate, lumiparietopsin (Figure 5A). Lumiparietopsin was stable up to $-70^{\circ} \mathrm{C}$ (Figure 5B, curve 2), and warming above this temperature caused a further blue-shift of the absorption spectrum (Figure 5B, 
curves 3-6), showing the formation of the next intermediate, which was stable up to $-30{ }^{\circ} \mathrm{C}$ (curve 6). The mixture containing this intermediate exhibited an absorption maximum at about $470 \mathrm{~nm}$, which is similar to the meta-I intermediate of vertebrate rhodopsin having a protonated-Schiff-base chromophore. Above $-30{ }^{\circ} \mathrm{C}$, this meta-I-like intermediate converted to the next intermediate having absorption maximum at near-UV region, which is similar to that of meta-II intermediate of vertebrate rhodopsin. Thus we refer to this deprotonated intermediate as metaparietopsin-II and the former protonated intermediate having $\lambda_{\max }$ at about $470 \mathrm{~nm}$ as metaparietopsin-I.

To elucidate the thermal reaction of metaparietopsin-II more precisely, spectral changes of parietopsin after irradiation with $>560 \mathrm{~nm}$-light were recorded at a fixed temperature $(-20$ and $-10{ }^{\circ} \mathrm{C}$ ). The transition from metaparietopsin-I to metaparietopsin-II was clearly observed at $-20^{\circ} \mathrm{C}$ (Figure 5C). At $-10^{\circ} \mathrm{C}$, metaparietopsin-II decayed to a protonated intermediate having $\lambda_{\max }$ at $445 \mathrm{~nm}$ (Figure 5D), which is similar to meta-III intermediate of vertebrate rhodopsin (metaparietopsin-III). Concurrent decay of both metaparietopsin-II and metaparietopsin-III was observed at $20^{\circ} \mathrm{C}$ (Figure 5E).

The low-temperature spectroscopy described above was carried out using parietopsin solubilized by CHAPS/PC. However, the presence of detergent may cause alteration of the photobleaching process. Accordingly, we also investigated the reaction process of parietopsin in membrane fractions of HEK293T cells (Figure 6A). We confirmed a transition from metaparietopsin-I to metaparietopsin-II in membrane fragments at $-20{ }^{\circ} \mathrm{C}$. However, we were unable to observe the formation of metaparietopsin-III at $-10{ }^{\circ} \mathrm{C}$ and 0 ${ }^{\circ} \mathrm{C}$, because of the significant turbidity of the membrane preparation.

We also prepared a parietopsin sample reconstituted into PC liposomes and subjected it to a time-resolved spectral measurement by using a CCD spectrophotometer (Figure 6B). The sample was irradiated with a 532-nm laser pulse, and the subsequent transient spectra were measured at $0{ }^{\circ} \mathrm{C}$ (Figure 6B). A set of difference spectra calculated by subtracting curve 2 from curves 3 - 8 in Figure 6B is shown in Figure 6C. To analyze the reactions kinetically, singular-value decomposition (SVD) and global-fitting analyses were applied, which gave two reaction components (Figure 6C, inset). The time constants of the first and second components were calculated to be $2.0 \pm 0.2$ and $100 \pm 3 \mathrm{sec}$, respectively. The first component (BS1 in Figure 6C, inset), with positive and negative peaks below 380 and 470 $\mathrm{nm}$, respectively, is almost identical to the spectral change from metaparietopsin-I to metaparietopsin-II (inset of Figure 5C). On the other hand, the second component (BS2 in Figure $6 \mathrm{C}$, inset,) shows a shape similar to the spectral change from metaparietopsin-II to metaparietopsin-III (inset of Figure 5D). Furthermore, we observed the concurrent decay of metaparietopsin-II and metaparietopsin-III to retinal and apoprotein after long incubation at $0{ }^{\circ} \mathrm{C}$ (Figure 6D). These results indicated that the irreversible bleaching process of parietopsin via meta-I-, meta-II- and meta-III-intermediates are not an artificial reaction in the presence of detergent but, rather, an intrinsic property of the protein. The photobleaching process of parietopsin was very similar to that of vertebrate rhodopsin.

\section{pH-dependent equilibrium between metaparietopsin-I and metaparietopsin-II}

It is well known that meta-I- and meta-II-intermediates of vertebrate rhodopsin are in $\mathrm{pH}$ dependent equilibrium, but the $\mathrm{pH}$-dependent profile is opposite to that expected from the $\mathrm{pH}$-dependency of the protonation state of the retinylidene Schiff base (38) : low pH favors metarhodopsin II having a deprotonated chromophore, and vice versa. On the other hand, the $\mathrm{pH}$ profile of meta-intermediates of invertebrate rhodopsin is consistent with a protonated state of the retinylidene Schiff base $(6,39)$. To examine whether the metaparietopsin-I and metaparietopsin-II form an equilibrium similar to that observed in vertebrate or invertebrate rhodopsin, the $\mathrm{pH}$-titration experiment of metaparietopsin was 
carried out. The transient spectra were measured at $0{ }^{\circ} \mathrm{C}$ using time-resolved spectroscopy at various $\mathrm{pH}$ 's (Figure 7). The relative amount of metaparietopsin-I at equilibrium was estimated and plotted against $\mathrm{pH}$ (Figure 7, inset). Since metaparietopsin-I having protonated chromophore increased at low $\mathrm{pH}$ (Figure 7, inset), the pH-dependency observed in metaparietopsins is similar to that in invertebrate metarhodopsins rather than that in vertebrate metarhodopsins.

\section{Discussion}

In the present study, we characterized the molecular properties of parietopsin and compared them to those of other opsins. The results indicated that parietopsin has features of both invertebrate and vertebrate visual opsins. Consistent with phylogenetic analysis, these results indicate that vertebrate visual opsins evolved from an ancestral opsin that exhibited molecular properties similar to those of invertebrate visual opsins.

The counterion stabilizing the protonated Schiff base is one of the most important residues for the molecular and biological functions of an opsin, such as color tuning, facilitation of photoisomerization, and stabilization of the inactive state for dark-noise reduction (40). We showed that Glu181 in parietopsin functions as the counterion in the dark state, similar to $\mathrm{G}_{\mathrm{o}}$-coupled rhodopsin and peropsin. We also demonstrated that Glu113 in the Q113E/ E181Q mutant acts as the counterion instead of Glu181, like $\mathrm{G}_{\mathrm{o}}$-coupled rhodopsin and peropsin (6). The interchangeability of positions 113 and 181 as the counterion, therefore, seems to be widely conserved over opsin groups including vertebrate visual and non-visual opsins/encephalopsins group having Glu181 as the counterion. Overall, our results suggest that the dark-state parietopsin structure around the Schiff base is more similar to that of invertebrate rhodopsins than of vertebrate rhodopsins (41).

The present study demonstrated that the photosensitivity of parietopsin was $70 \%$ of that of vertebrate visual opsins. Parietopsin is a photoreceptor protein in the parietal-eye photoreceptor cells, whose biological function is thought to be the global detection of dawn and dusk, sky polarization pattern and magnetoreception. Our result suggests that photosensitivity of non-visual opsins is not as high as visual opsins. We identified that the lower photosensitivity of parietopsin is attributable to its smaller $\varepsilon$ value. The $\varepsilon$ of bovine rhodopsin is 40600 and those of other vertebrate rhodopsins and cone pigments are also similar $(25,30,31)$. On the other hand, the $\varepsilon$ of invertebrate visual opsins $\left(\mathrm{G}_{\mathrm{q}}\right.$-coupled rhodopsin group) is known to be significantly lower than vertebrate visual opsins: 27000 for octopus rhodopsin (29), and 35000 for squid (28) and Drosophila (33) rhodopsins. The $\varepsilon$ of chicken Opn5m in Opn5 group, which is localized in chicken retina and brain, is 24600 (17). Thus vertebrate visual opsins have specifically acquired a high-photosensitivity system. We estimated the $\varepsilon$ of parietopsin to be 31700 , which is similar to those of invertebrate opsins. This result shows that although parietopsin is phylogenetically closely related to vertebrate visual opsins, parietopsin has not yet acquired the high-photosensitivity characteristic of vertebrate visual opsins.

We also investigated the structural change of parietopsin after light absorption by UVvisible spectroscopy. Extensive photochemical studies on vertebrate and invertebrate rhodopsins have revealed that the behaviors of metastable photoproducts are essentially different between them. In general, an opsin with the counterion at Glu181 (such as $\mathrm{G}_{0^{-}}$ coupled rhodopsin (19)) is bistable: that is, light converts it between two stable states, the original state and the acid metarhodopsin state. In contrast, vertebrate visual opsins exhibit an irreversible photobleaching process and finally dissociate into retinal and opsin. The photochemical study of parietopsin revealed that meta-I-, mata-II- and meta-III intermediates are successively formed like vertebrate visual opsins. However, the $\mathrm{pH}$ - 
equilibrium between metaparietopsin-I and metaparietopsin-II is similar to that of invertebrate rhodopsins. Thus, the structural change after light absorption of parietopsin showed that it is an "evolutionary intermediate" between invertebrate and vertebrate visual opsins.

The apparent difference between the $\mathrm{pH}$-dependency of the meta-I-to-meta-II equilibrium and the protonation state of the chromophore was recently accounted for by the presence of several substates of meta-II (42). Meta-II consists of two states, meta-IIa and meta-IIb. Additionally, meta-IIb is protonated at Glu134 $\left(\right.$ meta-IIbH ${ }^{+}$), a highly conserved residue forming the $\mathrm{D}(\mathrm{E}) \mathrm{RY}$ motif. The equilibrium among meta-I, meta-IIa and meta-IIb is independent of the environmental $\mathrm{pH}$, while that between meta-IIb and meta-IIbH ${ }^{+}$is $\mathrm{pH}-$ dependent. Therefore, the equilibrium between the meta intermediates shifts in favor of meta-IIbH $\mathrm{H}^{+}$when the protein takes a proton from the environment, resulting in a reduction in the amount of meta-I with a protonated Schiff base in acidic conditions. In parietopsin, the equilibrium between meta-I and meta-II simply reflects the protonation state of the chromophore. These results suggest the absence of an intermediate corresponding to meta$\mathrm{IIbH}^{+}$in the bleaching process of parietopsin. That is, parietopsin has acquired the mechanism to form an intermediate having a deprotonated Schiff base at neutral $\mathrm{pH}$ but has not yet acquired the hydrogen-bonding network system required to form the highly active conformation (meta-IIbH ${ }^{+}$). In this context, parietopsin would be an ideal candidate for identifying the amino acids forming the hydrogen-bonding network system from the chromophore to the cytoplasmic surface, which would elucidate how vertebrate visual opsins have acquired the molecular properties specialized for the vertebrate visual systems after branching from non-visual opsins.

\section{Supplementary Material}

Refer to Web version on PubMed Central for supplementary material.

\section{Acknowledgments}

We thank Dr. Take Matsuyama and Dr. E. Nakajima for reading our manuscript and helpful discussion. Western clawed frogs (Xenopus tropicalis) were provided from the Institute for Amphibian Biology (Hiroshima University, Hiroshima, Japan) through the National Bio-Resource Project (NBRP) of the MEXT, Japan.

This work was supported by Grants-in-Aid for Scientific Research (Ministry of Education, Culture, Sports, Science and Technology, Japan) to Y.S. (20227002, 60127090), Y.I. (23370070), and T.Y. (23770074), and a Grant for the Global Center of Excellence Program (A6) to Y.S., as well as U.S. NIH grant EY06837 to K.-W. Y.

\section{Abbreviations}

$\begin{array}{ll}\text { DM } & \text { n-dodecyl } \beta \text {-D-maltoside } \\ \text { CHAPS } & \text { 3-[(3-Cholamidopropyl)dimethylammonio]propanesulfonate } \\ \text { HEPES } & \text { N-(2-hydroxyethyl)piperazine-N'-2-ethanesulfonic acid } \\ \lambda_{\max } & \text { wavelength at the absorption maximum } \\ \text { PC } & \text { phosphatidylcholine } \\ \text { SVD } & \text { singular value decomposition }\end{array}$

\section{References}

1. Yau KW, Hardie RC. Phototransduction motifs and variations. Cell. 2009; 139:246-264. [PubMed: 19837030] 
2. Su CY, Luo DG, Terakita A, Shichida Y, Liao HW, Kazmi MA, Sakmar TP, Yau KW. Parietal-eye phototransduction components and their potential evolutionary implications. Science. 2006; 311:1617-1621. [PubMed: 16543463]

3. Solessio E, Engbretson GA. Antagonistic chromatic mechanisms in photoreceptors of the parietal eye of lizards. Nature. 1993; 364:442-445. [PubMed: 8332214]

4. Foa A, Basaglia F, Beltrami G, Carnacina M, Moretto E, Bertolucci C. Orientation of lizards in a Morris water-maze: roles of the sun compass and the parietal eye. J Exp Biol. 2009; 212:29182924. [PubMed: 19717673]

5. Nishimura T, Okano H, Tada H, Nishimura E, Sugimoto K, Mohri K, Fukushima M. Lizards respond to an extremely low-frequency electromagnetic field. J Exp Biol. 2010; 213:1985-1990. [PubMed: 20511511]

6. Terakita A, Koyanagi M, Tsukamoto H, Yamashita T, Miyata T, Shichida Y. Counterion displacement in the molecular evolution of the rhodopsin family. Nat Struct Mol Biol. 2004; 11:284-289. [PubMed: 14981504]

7. Zhukovsky EA, Oprian DD. Effect of carboxylic acid side chains on the absorption maximum of visual pigments. Science. 1989; 246:928-930. [PubMed: 2573154]

8. Sakmar TP, Franke RR, Khorana HG. Glutamic acid-113 serves as the retinylidene Schiff base counterion in bovine rhodopsin. Proc Natl Acad Sci U S A. 1989; 86:8309-8313. [PubMed: 2573063]

9. Nathans J. Determinants of visual pigment absorbance: identification of the retinylidene Schiff's base counterion in bovine rhodopsin. Biochemistry. 1990; 29:9746-9752. [PubMed: 1980212]

10. Cohen GB, Oprian DD, Robinson PR. Mechanism of activation and inactivation of opsin: role of Glu113 and Lys296. Biochemistry. 1992; 31:12592-12601. [PubMed: 1472495]

11. Emeis D, Kuhn H, Reichert J, Hofmann KP. Complex formation between metarhodopsin II and GTP-binding protein in bovine photoreceptor membranes leads to a shift of the photoproduct equilibrium. FEBS Lett. 1982; 143:29-34. [PubMed: 6288450]

12. Hofmann KP. Effect of GTP on the rhodopsin-G-protein complex by transient formation of extra metarhodopsin II. Biochim Biophys Acta. 1985; 810:278-281. [PubMed: 3933561]

13. Hubbard R, Kropf A. The action of light on rhodopsin. Proc Natl Acad Sci U S A. 1958; 44:130139. [PubMed: 16590155]

14. Hubbard R, St George RC. The rhodopsin system of the squid. J Gen Physiol. 1958; 41:501-528. [PubMed: 13491819]

15. Koyanagi M, Kubokawa K, Tsukamoto H, Shichida Y, Terakita A. Cephalochordate melanopsin: evolutionary linkage between invertebrate visual cells and vertebrate photosensitive retinal ganglion cells. Curr Biol. 2005; 15:1065-1069. [PubMed: 15936279]

16. Nagata T, Koyanagi M, Tsukamoto H, Terakita A. Identification and characterization of a protostome homologue of peropsin from a jumping spider. J Comp Physiol A Neuroethol Sens Neural Behav Physiol. 2010; 196:51-59. [PubMed: 19960196]

17. Yamashita T, Ohuchi H, Tomonari S, Ikeda K, Sakai K, Shichida Y. Opn5 is a UV-sensitive bistable pigment that couples with Gi subtype of G protein. Proc Natl Acad Sci U S A. 2010; 107:22084-22089. [PubMed: 21135214]

18. Kojima D, Mori S, Torii M, Wada A, Morishita R, Fukada Y. UV-sensitive photoreceptor protein OPN5 in humans and mice. PLoS One. 2011; 6:e26388. [PubMed: 22043319]

19. Koyanagi M, Terakita A, Kubokawa K, Shichida Y. Amphioxus homologs of Go-coupled rhodopsin and peropsin having 11-cis- and all-trans-retinals as their chromophores. FEBS Lett. 2002; 531:525-528. [PubMed: 12435605]

20. Nakamura A, Kojima D, Imai H, Terakita A, Okano T, Shichida Y, Fukada Y. Chimeric nature of pinopsin between rod and cone visual pigments. Biochemistry. 1999; 38:14738-14745. [PubMed: 10555955]

21. Koyanagi M, Kawano E, Kinugawa Y, Oishi T, Shichida Y, Tamotsu S, Terakita A. Bistable UV pigment in the lamprey pineal. Proc Natl Acad Sci U S A. 2004; 101:6687-6691. [PubMed: 15096614] 
22. Sato K, Yamashita T, Ohuchi H, Shichida Y. Vertebrate ancient-long opsin has molecular properties intermediate between those of vertebrate and invertebrate visual pigments. Biochemistry. 2011; 50:10484-10490. [PubMed: 22066464]

23. Sakai K, Imamoto Y, Yamashita T, Shichida Y. Functional analysis of the second extracellular loop of rhodopsin by characterizing split variants. Photochem Photobiol Sci. 2010; 9:1490-1497. [PubMed: 20886156]

24. Tsutsui K, Imai H, Shichida Y. E113 is required for the efficient photoisomerization of the unprotonated chromophore in a UV-absorbing visual pigment. Biochemistry. 2008; 47:1082910833. [PubMed: 18803408]

25. Tsutsui K, Imai H, Shichida Y. Photoisomerization efficiency in UV-absorbing visual pigments: protein-directed isomerization of an unprotonated retinal Schiff base. Biochemistry. 2007; 46:6437-6445. [PubMed: 17474760]

26. Kim JE, Tauber MJ, Mathies RA. Wavelength dependent cis-trans isomerization in vision. Biochemistry. 2001; 40:13774-13778. [PubMed: 11705366]

27. Wald G, Brown PK. The molar extinction of rhodopsin. J Gen Physiol. 1953; 37:189-200. [PubMed: 13109155]

28. Suzuki T, Uji K, Kito Y. Studies on cephalopod rhodopsin: photoisomerization of the chromophore. Biochim Biophys Acta. 1976; 428:321-338. [PubMed: 1276163]

29. Koutalos Y, Ebrey TG, Tsuda M, Odashima K, Lien T, Park MH, Shimizu N, Derguini F, Nakanishi K, Gilson HR, et al. Regeneration of bovine and octopus opsins in situ with natural and artificial retinals. Biochemistry. 1989; 28:2732-2739. [PubMed: 2525050]

30. Shichida Y, Imai H, Imamoto Y, Fukada Y, Yoshizawa T. Is chicken green-sensitive cone visual pigment a rhodopsin-like pigment? A comparative study of the molecular properties between chicken green and rhodopsin. Biochemistry. 1994; 33:9040-9044. [PubMed: 8049204]

31. Okano T, Fukada Y, Shichida Y, Yoshizawa T. Photosensitivities of iodopsin and rhodopsins. Photochem Photobiol. 1992; 56:995-1001. [PubMed: 1492139]

32. Dixon SF, Cooper A. Quantum efficiencies of the reversible photoreaction of octopus rhodopsin. Photochem Photobiol. 1987; 46:115-119. [PubMed: 3615630]

33. Ostroy SE. Characteristics of Drosophila rhodopsin in wild-type and norpA vision transduction mutants. J Gen Physiol. 1978; 72:717-732. [PubMed: 105082]

34. Becker RS, Freedman K. A comprehensive investigation of the mechanism and photophysics of isomerization of a protonated and unprotonated Schiff base of 11-cis-retinal. Journal of the American Chemical Society. 1985; 107:1477-1485.

35. Yoshizawa T, Shichida Y. Low-temperature spectrophotometry of intermediates of rhodopsin. Methods Enzymol. 1982; 81:333-354. [PubMed: 7098878]

36. Yoshizawa T, Wald G. Transformations of squid rhodopsin at low temperatures. Nature. 1964; 201:340-345. [PubMed: 14109991]

37. Shichida Y, Tokunaga F, Yoshizawa T. Circular dichroism of squid rhodopsin and its intermediates. Biochim Biophys Acta. 1978; 504:413-430. [PubMed: 718881]

38. Matthews RG, Hubbard R, Brown PK, Wald G. Tautomeric forms of metarhodopsin. J Gen Physiol. 1963; 47:215-240. [PubMed: 14080814]

39. Kropf A, Hubbard R. The mechanism of bleaching rhodopsin. Ann N Y Acad Sci. 1959; 74:266280. [PubMed: 13627857]

40. Tsutsui K, Shichida Y. Multiple functions of Schiff base counterion in rhodopsins. Photochem Photobiol Sci. 2010; 9:1426-1434. [PubMed: 20842311]

41. Murakami M, Kouyama T. Crystal structure of squid rhodopsin. Nature. 2008; 453:363-367. [PubMed: 18480818]

42. Mahalingam M, Martinez-Mayorga K, Brown MF, Vogel R. Two protonation switches control rhodopsin activation in membranes. Proc Natl Acad Sci U S A. 2008; 105:17795-17800. [PubMed: 18997017] 


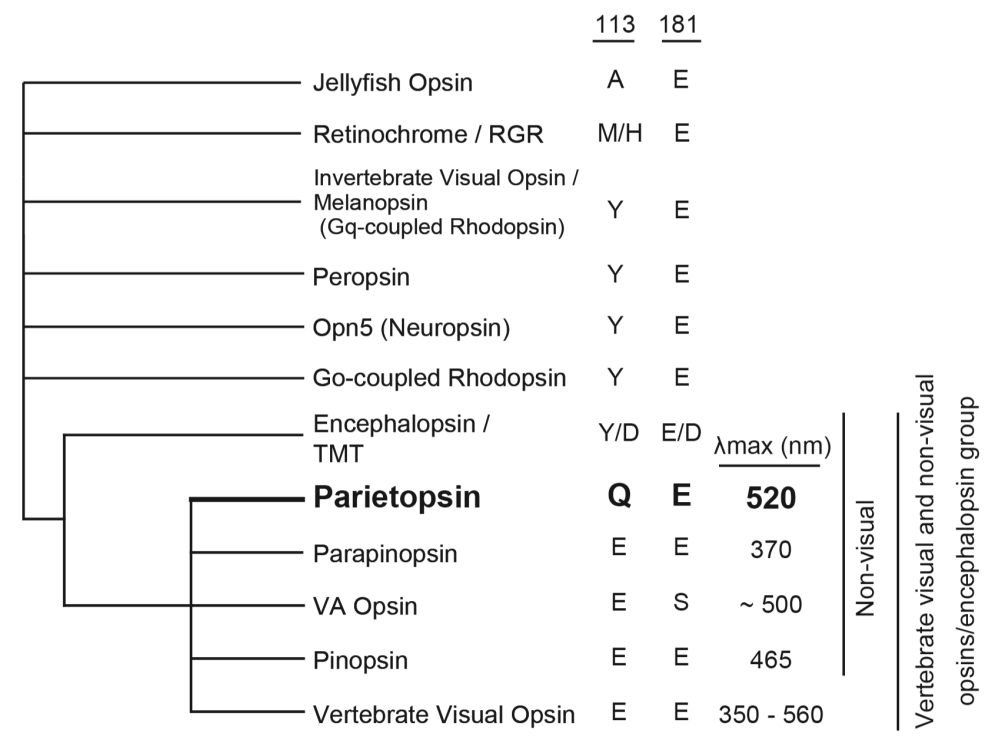

Figure 1.

Schematic phylogenetic tree showing the relationship between vertebrate visual and nonvisual opsins/encephalopsin group. Candidate residues for counterion (residues at 113 and 181 in the numbering system for bovine rhodopsin), and absorption maxima of each opsin groups are shown on the right. 


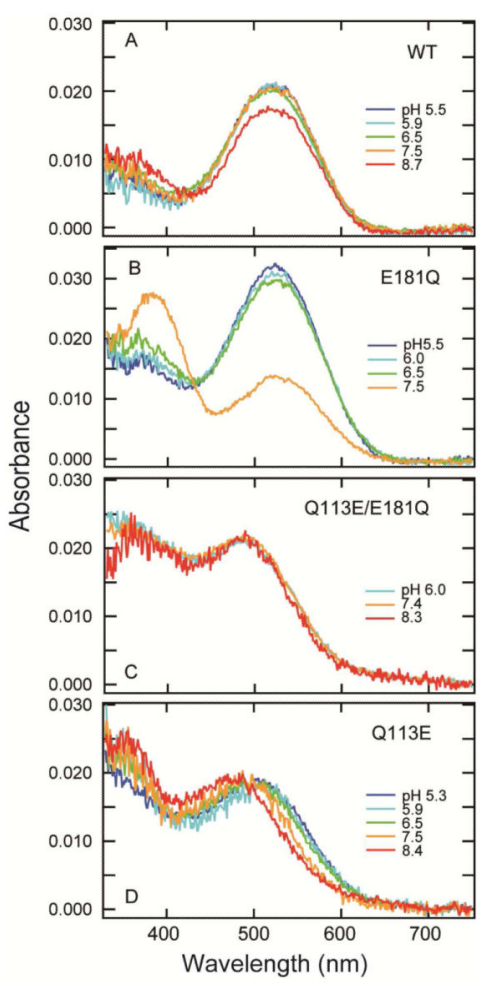

Figure 2.

$\mathrm{pH}$-dependency of dark spectra of wild-type parietopsin and mutants. Wild-type lizard parietopsin (A), E181Q (B), Q113E/E181Q (C) and Q113E (D) were purified with CHAPS/ PC buffer at $\mathrm{pH} 7.0$ containing $20 \%$ (w/v) glycerol, and $\mathrm{pH}$ was varied by adding small amounts of $\mathrm{HCl}$ or $\mathrm{NaOH}$. The numbers in graph traces indicate $\mathrm{pH}$ values. Absorption spectra were measured at $0{ }^{\circ} \mathrm{C}$. 

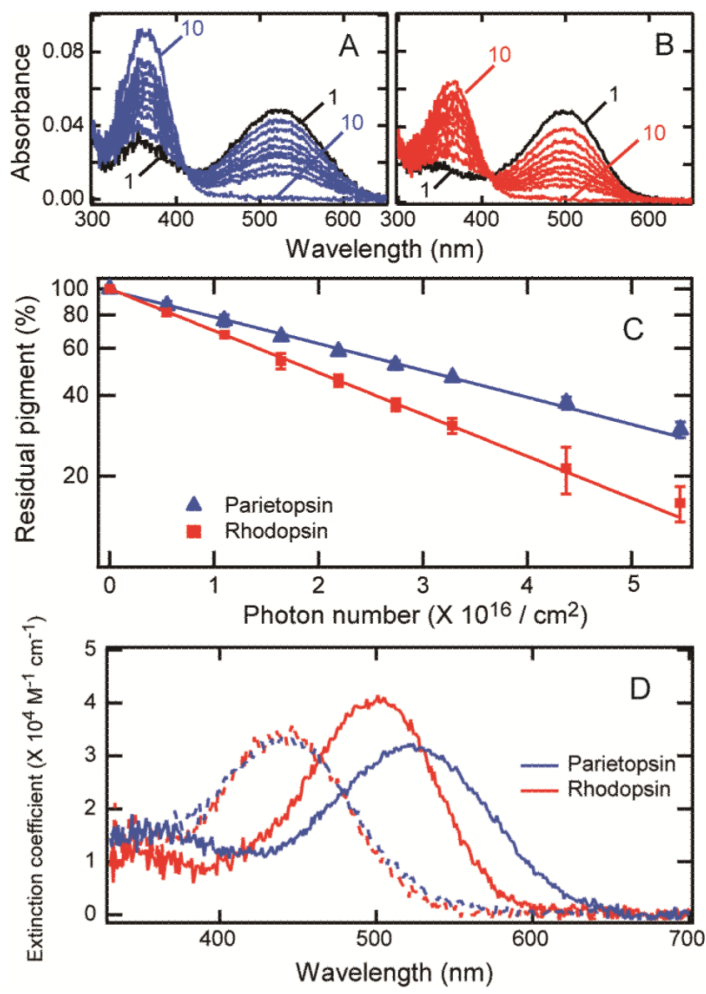

Figure 3.

Photosensitivity of parietopsin and bovine rhodopsin. (A) Lizard parietopsin (curve 1) and (B) bovine rhodopsin (curve 1) were irradiated successively with $500-\mathrm{nm}$ light at $0{ }^{\circ} \mathrm{C}$ and absorbance changes were monitored (curves 2-9). The samples were completely bleached at the end of the experiment (curves 10). (C) The amount of residual pigment was plotted against the incident photon number. The error bars represent the deviation of the two independent measurements. The photosensitivity of parietopsin relative to bovine rhodopsin was estimated from the slopes of the fitted lines. (D) Molar extinction coefficients $(\varepsilon)$ of parietopsin and bovine rhodopsin. Bovine rhodopsin and parietopsin were denatured by adding $\mathrm{HCl}$ (final $\mathrm{pH}<1.5$ ), which yielded identical denatured products (dashed lines). By normalizing the concentrations of parietopsin and bovine rhodopsin samples using the aciddenatured spectra, $\varepsilon$ of parietopsin relative to bovine rhodopsin was calculated to be $31700 \pm$ $500 \mathrm{M}^{-1} \mathrm{~cm}^{-1}$ at $520 \mathrm{~nm}$ and $29000 \pm 500 \mathrm{M}^{-1} \mathrm{~cm}^{-1}$ at $500 \mathrm{~nm}$ using the value of 40600 $\mathrm{M}^{-1} \mathrm{~cm}^{-1}$ at $500 \mathrm{~nm}$ for bovine rhodopsin. 


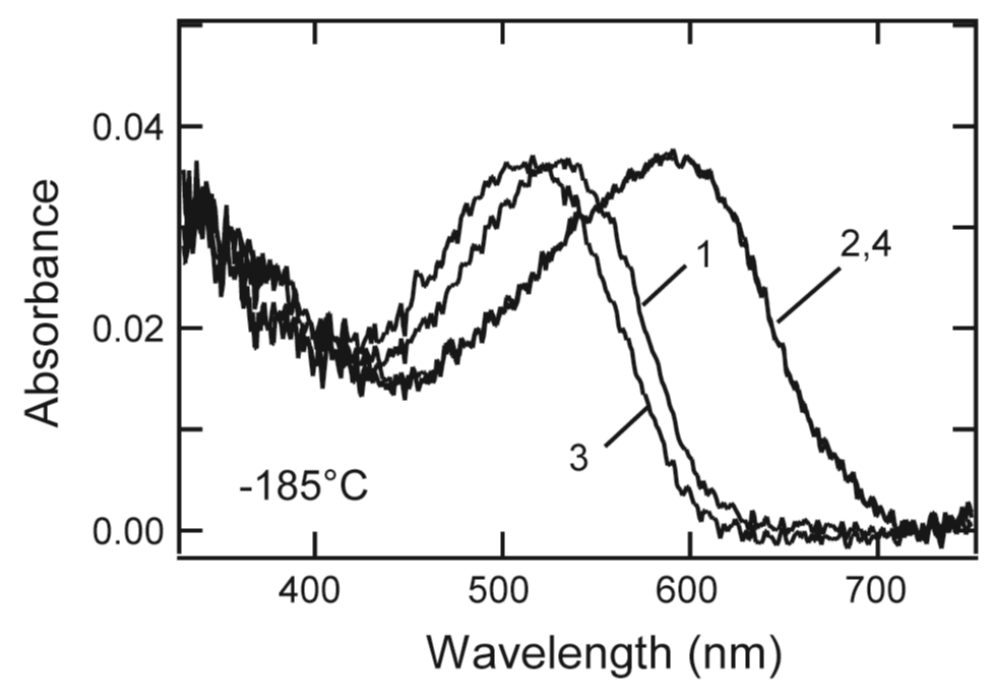

Figure 4.

Photochemical reaction of lizard parietopsin at $-185^{\circ} \mathrm{C}$. Parietopsin in CHAPS/PC buffer with $91 \%$ (w/v) glycerol was cooled to $-185^{\circ} \mathrm{C}$ (curve 1), and irradiated with $500 \mathrm{~nm}$ light $\left(<1 \mathrm{~mW} / \mathrm{cm}^{2}\right)$ for $315 \mathrm{~s}$ to form a photo-steady-state mixture (curve 2$)$. Then it was irradiated with deep-red light at $>630 \mathrm{~nm}\left(11 \mathrm{~mW} / \mathrm{cm}^{2}\right.$ ) for $300 \mathrm{~s}$ (curve 3 ), followed by irradiation with 500-nm light for $300 \mathrm{~s}$ (curve 4). 


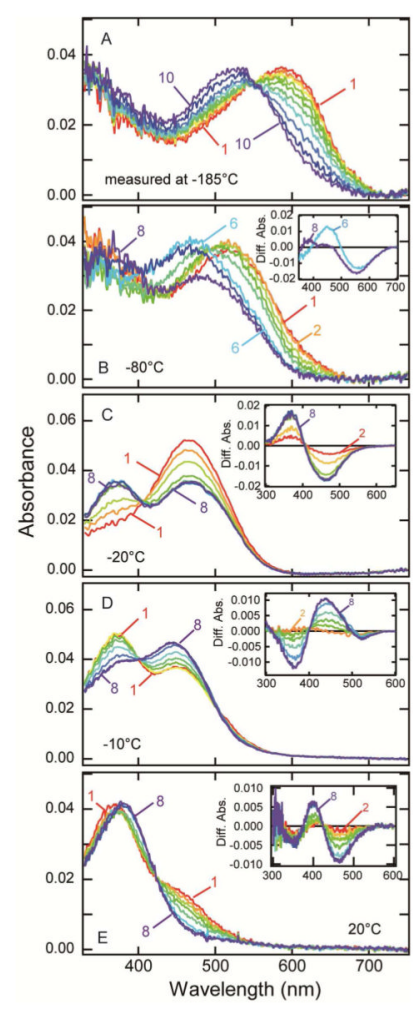

Figure 5.

Photobleaching process of lizard parietopsin. (A) Thermal reactions of bathoparietopsin.

The photo-steady-state mixture mainly containing batho intermediate (curve 1) was warmed to $-170{ }^{\circ} \mathrm{C}$ and recooled to $-185^{\circ} \mathrm{C}$ for the measurement of the spectrum (curve 2 ).

Similarly the sample was warmed to $-160,-150,-140,-130,-120,-110,-100$ and -90 ${ }^{\circ} \mathrm{C}$ in a stepwise manner, and the spectrum was recorded at $-185^{\circ} \mathrm{C}$ after each warming (curves 3-10). (B) After the measurements shown in panel (A), the absorption spectrum of the sample was recorded at $-80{ }^{\circ} \mathrm{C}$ (curve 1). It was warmed to $-70,-60,-50,-40,-30$, -20 and $-10{ }^{\circ} \mathrm{C}$ in a stepwise manner, and the spectra were measured at $-80{ }^{\circ} \mathrm{C}$ (curves 2-8). Inset: the difference spectra calculated by subtracting curve 1 from curves 6 and 8 . (C) Transition from metaparietopsin-I to metaparietopsin-II at $-20{ }^{\circ} \mathrm{C}$. Parietopsin sample was irradiated with $>560 \mathrm{~nm}$ light $\left(20 \mathrm{~mW} / \mathrm{cm}^{2}\right)$ for $15 \mathrm{sec}$. The spectra were recorded at 1.5 , $4.5,9,16,32,60,120$ and 150 min after irradiation (curves 1-8). Inset: the difference spectra calculated by subtracting curve 1 . (D) Transition from metaparietopsin-II to metaparietopsin-III was observed at $-10^{\circ} \mathrm{C}$. Parietopsin sample was irradiated with $>560$ $\mathrm{nm}$ light $\left(20 \mathrm{~mW} / \mathrm{cm}^{2}\right)$ for $15 \mathrm{sec}$. The spectra were recorded at 1.5, 4.5, 9, 16, 32, 60, 120 and 150 min after irradiation (curves 1-8). Inset: the difference spectra calculated by subtracting curve 1. (E) Dissociation of metaparietopsin-II and metaparietopsin-III into retinal and opsin at $20{ }^{\circ} \mathrm{C}$. Parietopsin sample was irradiated with $>500 \mathrm{~nm}$ light $(27 \mathrm{~mW} /$ $\mathrm{cm}^{2}$ ) for $20 \mathrm{sec}$. The spectra were recorded at 1.5, 5, 10, 15, 25, 60, 120 and $200 \mathrm{~min}$ after irradiation (curves 1-8). Inset: the difference spectra calculated by subtracting curve 1 . 


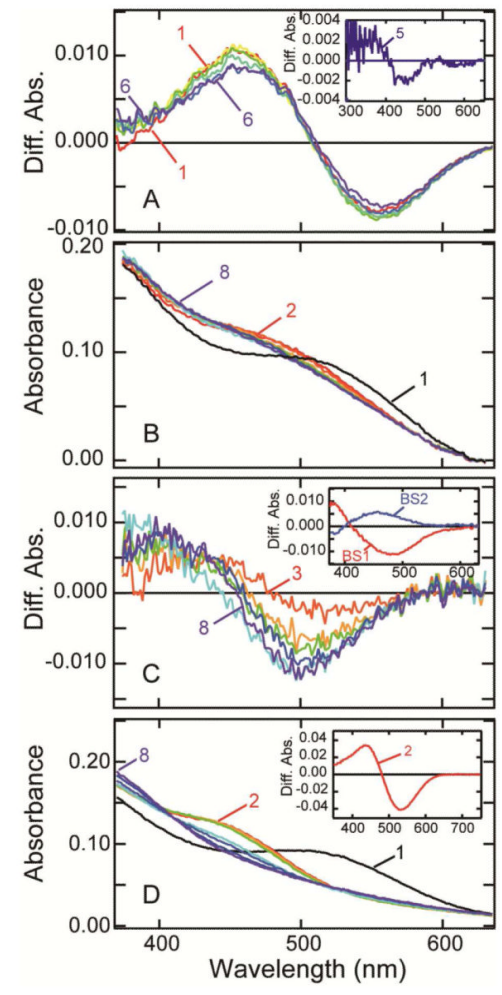

Figure 6.

Photoreaction of detergent free parietopsin in membranes. (A) Transient absorption spectra of parietopsin in HEK293T membrane fragments at $-20^{\circ} \mathrm{C}$. The sample was prepared by the sucrose flotation method and added $50 \%(\mathrm{w} / \mathrm{v})$ glycerol. The spectra were recorded at $1.5,5,10,30,60$ and $120 \mathrm{~min}$ after irradiation with $>560 \mathrm{~nm}$-light $\left(20 \mathrm{~mW} / \mathrm{cm}^{2}\right)$ for $15 \mathrm{sec}$. Difference spectra was calculated by subtracting the spectrum recorded before irradiation from the spectra after irradiation (curves 1-6). Inset: the difference spectra between curve 1 (1.5 min) and curve 5 (60 min). (B) Transition from metaparietopsin-I to metaparietopsin-II plus metaparietopsin-III in PC liposomes. Parietopsin in PC liposomes (curve 1) was irradiated with a 532-nm laser pulse at $0{ }^{\circ} \mathrm{C}$. The spectra recorded at $0.01,0.05,0.5,1,60$, 600, $1800 \mathrm{sec}$ after irradiation (curve 2-8) are displayed. (C) Difference spectra calculated by subtracting curve 2 from curves 3-8 shown in (B). Inset: Two b-spectra (BS1 and BS2) calculated from the spectral change shown in Figure 6C. BS1 and BS2 indicate transitions from metaparietopsin-I to metaparietopsin-II and from metaparietopsin-II to metaparietopsin-III, respectively. (D) Transition from metaparietopsin-II and metaparietopsin-III to retinal and apoprotein in PC liposomes. Parietopsin in PC liposomes (curve 1) was irradiated with $>560 \mathrm{~nm}$ light $\left(20 \mathrm{~mW} / \mathrm{cm}^{2}\right)$ for $5 \mathrm{~min}$ at $0{ }^{\circ} \mathrm{C}$. The spectra were recorded at 5, 30 and $60 \mathrm{~min}$ and 2, 5, 10 and 14 hours after irradiation (curves 2-8). Inset: the difference spectra between curve 1 and curve 2, showing that metaparietopsin-II and metaparietopsin-III are formed by irradiation. 


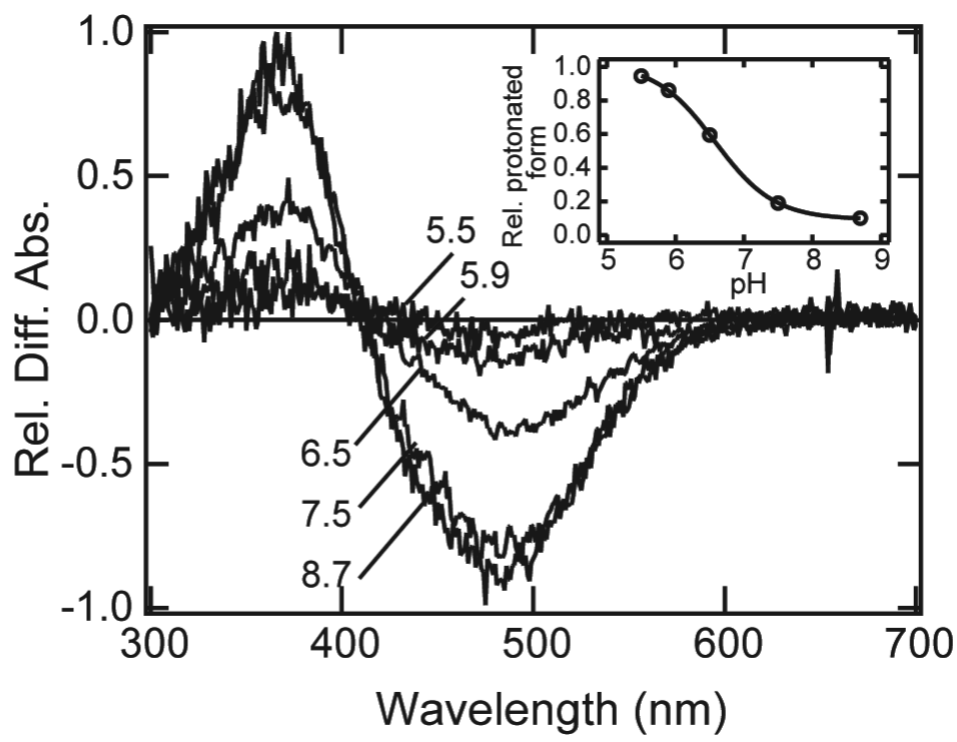

Figure 7.

pH-equilibrium between metaparietopsin-I and metaparietopsin-II. The samples were purified with CHAPS/PC buffer containing 20\% (w/v) glycerol. Transient spectra from metaparietopsin-I to metaparietopsin-II were recorded at $0{ }^{\circ} \mathrm{C}$ by using time-resolved CCD spectrophotometer. The difference spectrum at each $\mathrm{pH}$ was calculated by subtracting the spectrum measured at $10 \mathrm{~ms}$ after the flash irradiation from that of the equilibrium state measured at $100 \mathrm{sec}$. It should be noted that the spectrum measured at $10 \mathrm{~ms}$ after the irradiation is the composite of only two components, the spectra of metaparietopsin-I and unreacted parietopsin. The amount of unreacted parietopsin was determined by hydroxylamine bleaching of metaparietopsin-I after the time-resolved measurements, and subtracted from the spectra at $10 \mathrm{~ms}$ to calculate the amount of metaparietopsin-I generated by the flash. In the main panel, difference spectra were normalized at their negative peaks $(490 \mathrm{~nm})$ relative to the amount of metaparietopsin-I produced by the irradiation. Inset: The ratio of metaparietopsin-I was estimated by the difference absorbance at $490 \mathrm{~nm}$ in the main panel. They were plotted against $\mathrm{pH}$, and the curve was fitted by Henderson-Hasselbalch equation. 